\title{
Effects of post-learning activities on the retention of paired-associates'
}

\author{
JAMES E. CARLSON ${ }^{2}$, FREDERIC J, BOERSMA, AND RODHEY C. CONKLIN ${ }^{3}$
}

UNIVERSITY OF ALBERTA

The effects of four different post-learning activities on the retention of 10 low-high meaningful paired-associate items were examined. Retention measures were collected after seven days. Ss receiving post-learning activities had significantly higher mean retention scores than $S$ s not receiving such treatment. It was also found that retention scores were related to strategy level employed during learning. The results were discussed in terms of an interaction between intention to learn, the development of better plans to aid recall during post-leaming activities, and an overleaming effect.

In a recent study, Boersma, Conklin, \& Carlson (1966) suggested that the writing out of associative strategies after learning may force Ss to actively conceptualize acquisition strategies and thus strengthen S-R connections. They referred to these post-learning verbalizations as "post-organizers." The postorganizer hypothesis was advanced as a result of a study in which some Ss (STRATEGY treatment) were asked to report associative learning strategies, while others (NONSTRATEGY treatment) were not. The STRATEGY group retention mean was found to be significantly higher than was that of the NONSTRATEGY group. As was pointed out, however, Ss in the STRATEGY treatment were exposed to the items while writing out strategies and therefore exposure time was not constant across the two treatments. The authors suggested that further studies which separate the effects of post-organizing from overlearning are necessary.

The present study is concerned with further investigation into the concept of post-organizers, and specifically with comparing the retention scores of Ss in a treatment where verbal reports are made with that of Ss in treatments involving other post-learning activities. It was hypothesized that $\mathrm{Ss}$ in the strategy reporting treatment would retain significantly more items than would Ss in the other treatment groups. Method

Sixty educational psychology undergraduates served as Ss in this experiment. They were tested individually and randomly assigned to four treatments such that each group contained 15 Ss. Three groups (REPORT, REPETITION, LOOK) were given a series of learning and test trials identical to that used by Boersma et al (1966). That is, learning and test trials were presented at a $3 \mathrm{sec}$ rate with an intertrial interval of $10 \mathrm{sec}$. A different random order for items was used on each trial, and all Ss were run to a criterion of two perfect consecutive trials. An oral recall procedure was employed for test trials. Once an item was responded to correctly twice in a row it was removed from the list. The 10 pairs of low-high meaningful items were the same as those used by Boersma et al. The fourth treatment (OVERLEARNING) differed only in that all Ss were run to a criterion of elght consecutive correct trials per pair.

At the conclusion of the learning task Ss in the REPORT treatment were given 40 sec per item to write out how they attempted to form each association. Thus, the REPORT group in the present study is the same as the STRATEGY group in the study by Boersma et al. Ss in the REPETITION treatment were also exposed to each pair at the end of the learning task. But their task was to write out each pair as many times as they wished during the $40 \mathrm{sec}$ period. In the LOOK treatment, Ss were asked only to visually examine each pair during the 40 sec period. Ss in the OVERLEARNING treatment were given six learning and test trials, in addition to those received by $S s$ in the other three groups. Consequently, Ss in this group were exposed to each item for approximately the same period of time $(36 \mathrm{sec})$ following the two consecutive correct response criterion.

After a period of seven days all Ss were tested for retention, and then asked to report in writing how they originally tried to learn each pair. A recall procedure, similar to that used for test trials, was employed for the retention task. But now Ss were given $10 \mathrm{sec}$ per item to write down their response. In order to discourage rehearsing of the items during the seven day interval, Ss were told that they were to participate in a different task when they returned. Results and Discussion

In the analyses discussed below, the data from the two treatment groups in the study by Boersma et al (1966) were included. Comparisons were thus made among six treatment groups.

In order to test whether Ss in the various treatments differed with respect to learning ability, the number of trials required to reach the initial criterion of two successive correct responses on each item was recorded. These scores were then summed over all items for each $S$. An analysis of variance on this variable showed that there were statistically significant differences among treatment means $(F=3.51$, $\mathrm{p}<.01$ ). The Newman-Keuls procedure (Winer, 1962 , pp. 80-85) was used to determine which means dif- 
Table 1. Retention Means and Standard Deviations by Treatment

\begin{tabular}{lccc} 
Treatment & $\mathrm{n}$ & Mean & Standard Deviation \\
\hline Strategy & 20 & 7.85 & 1.49 \\
Nonstrategy & 20 & 3.85 & 1.98 \\
Report & 15 & 6.87 & 2.16 \\
Repetition & 15 & 6.60 & 2.78 \\
Look & 15 & 8.67 & 1.30 \\
Overlearning & 15 & 7.27 & 2.62 \\
\hline
\end{tabular}

Note: Strategy and Nonstrategy treatments from Boersma et al., (1966).

fered statistically. Mean number of trials was found to be significantly greater in the OVERLEARNING group when compared with all other group means $(p<.05)$, but no other pairs of means differed significantly from each other. Thus, Ss reached a criterion of two successive correct responses per item faster when items were removed from the list, than when they were not.

The number of items retained after the seven day delay period was also recorded for each $S$. Retention means and standard deviations for each treatment are presented in Table 1. An analysis of variance on mean retention scores indicated that there were statistically significant differences between treatments $(F=10.85, p<.01)$. The Newman-Keuls technique was used again to determine which pairs of means differed significantly from each other. Retention means for all post-learning treatments were significantly higher than the mean of the NONSTRATEGY group $(p<.01)$, and performance on the LOOK treatment was found to be significantly better than performance on the REPORT and REPETITION treatments $(p<.05)$. No other pairs of means differed significantly from each other.

The classification scheme for associative strategies developed by Martin, Boersma, \& Cox (1965) was used to score each verbal report collected at the conclusion of the retention task. These scores were then summed over items to obtain a total retention strategy score for each S. The Mann-Whitney $\mathrm{U}$ test (Siegel, 1956, pp. 116-127) revealed no significant differences between mean total strategy scores for the six treatments.

A Spearman rank order correlation coefficient between total retention and strategy scores for all 100 Ss in the six treatments was found to be significantly different from zero $\left(r_{s}=.364, p<.01\right)$. This coefficient, although low, tends to support the strategy classification scheme developed by Martin et al (1965) in that the data shows a significant relationship between strategy level employed during learning and retention of low-high meaningful paired-associate material.

In short, the results of this study do not support the hypothesis that Ss in the REPORT treatment would retain significantly more items than would $\mathrm{Ss}$ in the other treatments. It was found that other post-learning activities, as well as overlearning to eight consecutive correct responses per item, aided retention at least as well as the writing out of associative strategies.

The findings of the present study, as well as those of Boersma et al (1966), might better be explained in terms of intention to learn. Miller, Galanter, \& Pribram (1960) maintain that intention to learn results in the constructing of a plan to guide recall. It is possible that re-exposure to the items after initial learning, or the long period of learning and test trials in the OVERLEARNING group, served to cue Ss as to the nature of the second task, and that during these postlearning activities Ss developed better plans to aid recall. But it is unlikely that this was the main factor contributing to better performance since precautions were taken to minimize cues relative to the second task, and Ss were removed from the sample if they studied for retention. Moreover, Boersma et al found no statistically significant differences in total acquisition strategy scores collected at the conclusion of the retention task between STRATEGY and NONSTRATEGY treatments. Thus, the data can probably be better explained in terms of an extremely strong overlearning effect. The interaction, however, between intention to learn with re-exposure to items, the development of better plans to aid recall during postlearning activities, and overlearning should not be ignored.

\section{References}

Boersma, F. J., Conklin, R. C., \& Carlson, J. E. Effects of reporting associative strategies on the retention of paired associates. Psychon. Sci., 1966, 5, 463-464.

Martin, C. J., Boersma, F. J., \& Cox, D. L. A classification of of associative strategies in paired-associate learning. Psychon. Sci., 1965, 3, 455-456.

Miller, G. A., Galanter, E., \& Pribram, K. Plans and the structure of behavior. New York: Holt, 1960.

Siegel, S. S. Nonparametric statistics for the behavioral sciences. New York: McGraw-Hill, 1956.

Winer, B. J. Statistical principles in experimental design. New York: McGraw-Hill, 1962.

\section{Notes}

1. This research was supported in part by A.A.C.E.R. Grant 11365 .

2. Now at the University of Pittsburgh.

3. Now at the University of Calgary. 